\title{
Corticosteroids and corneal epithelial wound healing
}

\author{
G. PETROUTSOS, R. GUIMARAES, J. P. GIRAUD AND Y. POUliQuen
}

From the Centre de Recherche d'Ophtalmologie, INSERM U 86, Hôtel-Dieu, Place du Parvis Notre-Dame, 75181 Paris Cedex 04, France

SUMmARY The effect of corticosteroids on the re-epithelialisation of corneas from which the epithelium was removed has been determined by fluorescein staining, photography, and light microscopy. Our results suggest that hydroxymethyl progesterone $1.05 \%(\mathrm{p}<0.05)$, prednisolone $1.0 \%(\mathrm{p}<0.001)$, and dexamethasone $0.1 \%(\mathrm{p}<0.001)$ administered 6 times a day retard the epithelial wound healing compared with control animals which received isotonic $\mathrm{NaCl}$.

The effect of corticosteroids on the corneal epithelium is important for a number of reasons. Corticosteroids are the most effective drugs for the nonspecific suppression of inflammation. ${ }^{\prime}$ They prevent corneal neovascularisation in clinical and experimental work $^{23}$ and are widely used in current ophthalmology. Finally the integrity ${ }^{4}$ and healthy quality ${ }^{5}$ of the corneal epithelium are essential to the health of the cornea. Anti-inflammatory steroids may delay the healing of corneal stromal wounds, ${ }^{67}$ produce glaucoma,${ }^{8}$ and increase the liability to infection. ${ }^{910}$

This paper reports experimental results of the effects of different corticosteroids on the healing of rabbit corneal epithelium.

\section{Material and methods}

Experimental animals. Twenty pigmented rabbits of both sexes weighing 2 to $3 \mathrm{~kg}$ each were used in this study. Each animal was examined in a slit-lamp microscope and no evident pathological findings were noted prior to the experiment.

Epithelial healing study. Forty eyes were divided in 4 groups of 10: Group A received topical isotonic $\mathrm{NaCl}$ solution used as control; group B received topical commercial hydroxymethyl progesterone $1.05 \%$ solution (Medrysone); group C received topical commercial prednisolone sodium phosphate $1.0 \%$ solution (Solucort); group D received topical commercial dexamethasone sodium phosphate $0.1 \%$ solution (Decadron phosphate). All these drugs were given 6 times a day.

Correspondence to Dr G. Petroutsos, Laboratoire d'Ophtalmologie. Hôtel-Dieu, Place du Parvis Notre-Dame. 75181 Paris Cedex 04. France, INSERM U 86.
The method described by Moses et al. ${ }^{11}$ was used for removal of the corneal epithelium. Our tube has an internal diameter of $7 \cdot 3 \mathrm{~mm}$ at the tip.

Rabbits were anaesthetised with sodium pentobarbital administered in a marginal ear vein $(25 \mathrm{mg}$ per $\mathrm{kg}$ body weight). Two drops of Novesine (oxybyprocaine hydrochlorate $0.4 \%$ ) were instilled into each eye. Each eye was then gently proptosed, and the lip of the iodine tube was wiped on a filter paper and held against the cornea for 3.5 minutes. Recording of the lesion was by photography. The cornea was stained with one drop of $0.5 \%$ fluorescein (without preservatives) and then washed with 2 drops of isotonic $\mathrm{NaCl}$ solution. The lesions were photographed on Kodak Tri-X film 4 times a day until the complete healing of the corneal epithelial wound, which was determined by the absence of corneal fluorescein uptake. An annular electronic flash covered with a Wratten $47 \mathrm{~B}$ filter was fixed round the objective of a slit-lamp, and the objective was covered with a Wratten 12 filter to obtain a good contrast on black-and-ivhite films.

With a Quantimet 720 (Cambridge Instruments, UK) the fluorescein-stained areas were measured and converted to square millimeters.

For each eye a healing curve was obtained by plotting successive areas of the wound against time. The best fitting curve by the least squares method was obtained by means of a linear regression.

The diameter of the first corneal wound for each eye was also measured at 6 hours.

Histological study. Four days after treatment 4 eyes from each group were enucleated, stained with haematoxylin and eosin, and prepared for histological examination.

Under the microscope we counted the total number of cellular nuclei on the 4 specimens on a $0.35 \mathrm{~mm}$ 


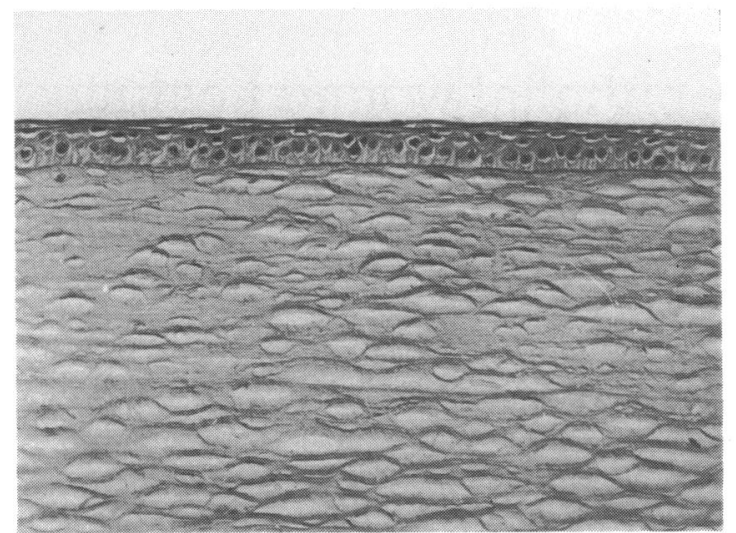

$1 \mathrm{~A}$

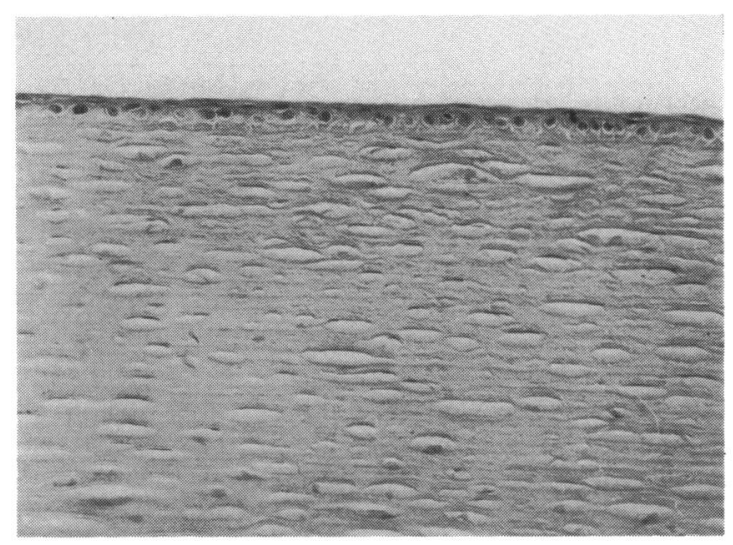

$1 \mathrm{C}$

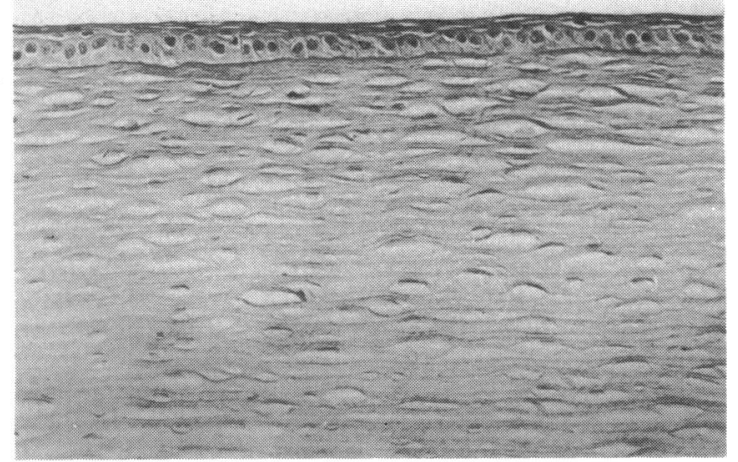

1B

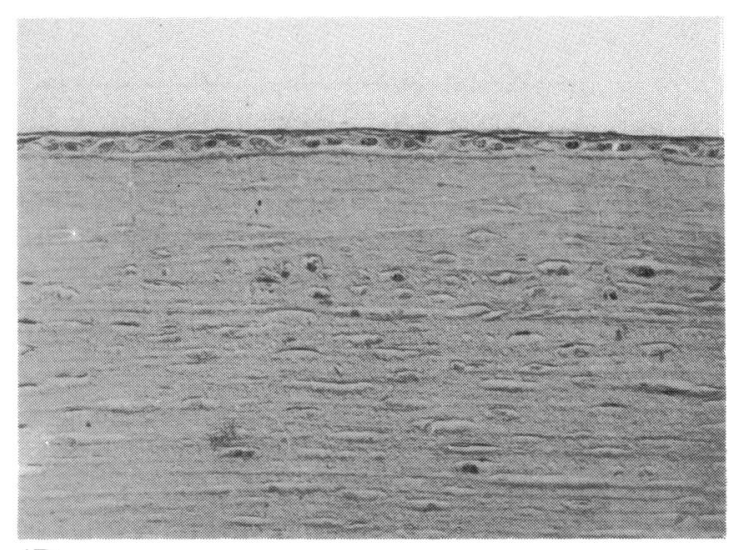

1D

Figs. 1A, B, C, D Histological cross-sections of healed epithelium after 4 days of treatment. ( $\times 622)$. A: Top left, control cornea. B: Top right, cornea treated by hydroxymethyl progesterone. C: Left cornea treated by prednisolone $0 \cdot 1 \%$. D: Right cornea treated by dexamethasone $1.0 \%$. Note the difference appearing: in the cellular aspect; in the number of layers; in the cellular nuclei.

length of object. Six different levels of the same paraffin block were studied. These measures were taken on 3 different sectors of the same cornea in a central zone of $4 \mathrm{~mm}$ radius.

\section{Results}

The mean diameter of the epithelial corneal wounds at 6 hours for each group ranged from $7 \cdot 85$ to $7.71 \mathrm{mn}$ (Table 1). By Student's $t$ test the difference was not statistically significant, $p>0 \cdot 05$. Table 2 gives the slopes computed by the least squares linear regression method for all the 40 healing rates individually. The mean rates for each group are also shown.

As shown in Table 2, the difference between the saline-treated group A and the others groups was statistical'v significant (student's $t$ test) at the level $\mathrm{p}<0.05$ for group $\mathrm{B}$ and $\mathrm{p}<0.001$ for groups $\mathrm{C}$ and $\mathrm{D}$.

Table 3 shows the mean number of cellular nuclei on a $0.35 \mathrm{~mm}$ length for each group. There was no statistically significant difference $(p>0.05)$ between the control group A and group B. There is a statistically significant difference $(p<0.001)$ between group $A$ and groups $C$ and $D$.

In the control group the anterior epithelium was 3 to 4 layers thick; the basal layer was formed by tall

Table 1 Mean diameter $(\mathrm{mm}) \pm$ standard deviation of ulcers at 6 hours

\begin{tabular}{llll}
\hline Group $A$ & Group B & Group C & Group D \\
\hline $\mathrm{m}_{1}=7.64 \pm 0.35$ & $\mathrm{~m}_{2}=7.69 \pm 0.25$ & $\mathrm{~m}_{3}=7 \cdot 58 \pm 0 \cdot 20$ & $\mathrm{~m}_{4}=7 \cdot 71 \pm 0.32$ \\
- & $\mathrm{p}>0.05$ & $\mathrm{p}>0.05$ & $\mathrm{p}>0.05$ \\
\hline
\end{tabular}


Table 2 Rate of decrease of area of epithelial wound $\left(\mathrm{mm}^{2} / \mathrm{h}\right)$

\begin{tabular}{llll}
\hline $\begin{array}{l}\text { Group A } \\
\text { Control }\end{array}$ & $\begin{array}{l}\text { Group B } \\
\text { Hydroxymethyl } \\
\text { progesterone } \\
1.05 \%\end{array}$ & $\begin{array}{l}\text { Group C } \\
\text { Prednisolone } \\
I .0 \%\end{array}$ & $\begin{array}{l}\text { Group D } \\
\text { Dexamethasone } \\
0.1 \%\end{array}$ \\
\hline 1.25 & 1.06 & 0.74 & 0.48 \\
1.07 & 1.11 & 0.60 & 0.74 \\
1.15 & 1.08 & 0.53 & 0.52 \\
1.14 & 1.05 & 0.82 & 0.53 \\
1.32 & 0.98 & 0.61 & 0.48 \\
1.08 & 0.85 & 0.54 & 0.42 \\
1.13 & 1.15 & 0.53 & 0.54 \\
1.02 & 1.05 & 0.81 & 0.61 \\
1.17 & 0.89 & 0.62 & 0.75 \\
1.40 & 0.99 & 0.87 & 0.87 \\
\hline
\end{tabular}

$\alpha \mathrm{m}_{1}=1 \cdot 17 \pm 0 \cdot 12 \quad \mathrm{~m}_{2}=1 \cdot 02 \pm 0 \cdot 09 \quad \mathrm{~m}_{3}=0 \cdot 67 \pm 0 \cdot 13 \quad \mathrm{~m}_{4}=0 \cdot 59 \pm 0 \cdot 15$ $\beta \quad-\quad \mathrm{p}<0.05 \quad \mathrm{p}<0.001 \quad \mathrm{p}<0 \cdot 001$

Each value listed presents the healing rate obtained from an animal. $\alpha=$ Mean healing rate \pm standard deviation.

$\beta=p$ values.

Table 3 Mean number of cellular nuclei \pm standard deviation per $0.35 \mathrm{~mm}$ on histological preparation

\begin{tabular}{cccl}
\hline Group $A$ & Group B & Group C & Group D \\
\hline $\mathrm{m}_{1}=73 \cdot 20 \pm 8 \cdot 81$ & $\mathrm{~m}_{2}=69 \cdot 25 \pm 10 \cdot 30$ & $\mathrm{~m}_{3}=41 \cdot 10 \pm 7 \cdot 80$ & $\mathrm{~m}_{4}=44 \cdot 21 \pm 7 \cdot 10$ \\
- & $\mathrm{p}>0 \cdot 05$ & $\mathrm{p}<0 \cdot 001$ & $\mathrm{p}<0 \cdot 001$ \\
\hline
\end{tabular}

polyhedral cells with no apparent histological lesions (Fig. 1A). The epithelium in the group B specimen did not differ much from that of the control group. There were only a few foci where the upper epithelial layers consisted of flattened parakeratotic cells (Fig. 1B).

In contrast, the epithelium of groups $\mathrm{C}$ and $\mathrm{D}$ was one or 2 layers thick. The cells of the basal layer seemed to have lost their junctional units, and the superficial layers were formed of extremely flattened cells with hyperchromatic nuclei (Figs. 1C, D). The histological study was restricted to the centre of the lesion.

\section{Discussion}

There are certain conditions in which, despite a break in the corneal epithelium, we are obliged to administer topical corticosteroids. In order to obtain information on the epithelial regeneration of the cornea when treated with different corticosteroids the healing process of a superficial epithelial corneal ulcer was measured. Histological studies have been performed to evaluate the quality of the regenerated epithelium. For the removal of the corneal epithelium we used a reproducible method ${ }^{11}$ which respects ${ }^{12}$ the epithelial basal membrane.
Our results suggest that topical application of prednisolone $1.0 \%$ and dexamethasone $0.1 \% 6$ times a day decreases $(p<0 \cdot 001)$ the epithelial healing rates in comparison with those of the control group. Hydroxymethyl progesterone also produces a slight $(p<0 \cdot 05)$ retardation in the epithelial wound healing. There is a statistically significant difference at the 0.001 level between the mean healing rates of group B (hydroxymethyl progesterone) and groups C (prednisolone) and D (dexamethasone).

Our results are confirmed by the histological study. The total number of cellular nuclei was reduced $(p<0 \cdot 001)$ for the groups $C$ and $D$ and histological alterations have been observed. The number of cellular nuclei in group B did not differ from that of the control group, and the histological appearance in both groups was almost the same.

In agreement with our results Aquavella et al. ${ }^{7}$ reported that in epithelial abrasions the retardation of healing observed after prednisolone treatment was statistically significant but transient in nature. They suggested that this effect is clinically unimportant.

Ho and Elliot ${ }^{13}$ found that topical application of 16 drops per day of vehicle or dexamethasone sodium phosphate (Decadron) decreased the epithelial healing rate when compared with saline drops administered 4 times daily. They suggested that the frequent instillation of the drops and not the contents may produce this effect. The vehicle used, containing $0.2 \%$ benzalkonium chloride, is toxic ${ }^{14}$ to the epithelium at this concentration.

Recently Srinivasan and Kulkarni ${ }^{16}$ demonstrated that $1.0 \%$ prednisolone acetate and $0.1 \%$ dexamethasone did not affect the course of re-epithelialisation after partial corneal epithelial denudation. On the contrary the healing rate was significantly retarded after complete corneal denudation. We think that the larger diameter of the epithelial denudation used in our method explains the different results obtained. Moreover in this study the drugs were administered 3 times daily.

Epithelial punctate keratitis has also been reported in human corneas after topical application of prednisolone ${ }^{17}$ and important morphological changes in the epithelium of rabbit cornea.$^{18}$ It has been shown that repeated application of prednisolone $1.0 \%$ and dexamethasone $0.1 \%$ can retard the epithelial wound healing of a superficial epithelium ulcer.

For hydroxymethyl progesterone, a synthetic corticosteroid which is an effective anti-inflammatory agent for certain external conditions ${ }^{19}$ free from the propensity to raise the intraocular pressure,$^{20}$ the results in our model proved that the epithelial wound healing was slightly retarded. The purpose of this study was to facilitate recognition of the adverse effect of the corticosteroids and to stress the need for further investiga- 
tion, both in vivo and in vitro, the effects of these drugs on the corneal epithelium under normal and abnormal epithelial healing.

This study was supported by INSERM U 86 grants.

We thank the Essilor Company for the Automatic Image Analyser.

\section{References}

1 Leibowitz HM. Kupferman A. Bioavailability and therapeutic effectiveness of topically administered corticosteroids. Trans Acad Ophthalmol Otolaryngol 1975; 79: 78-88.

2 Ashton V, Gook C. Langhan M. Effect of cortisone on vascularization and opacification of the cornea induced by alloxan. $B r J$ Ophthalmol 1951; 35: 718-24.

3 Schwartz B. Corticosteroids and the eye. Int Ophthalmol Clin 1966; 6: 753-1104.

4 Friend J. Thoft RA. Functional competence of regenerating ocular surface epithelium. Invest Ophthalmol Visual Sci 1978; 17: 134-9.

5 Gasset AR, Dohlman CH. The tensile strength of comeal wounds. Arch Ophthalmol 1968; 79: 595-602.

6 Sugar J, Chandler WJ. Experimental corneal wound strength. Arch Ophthalmol 1974; 92: 248-9.

7 Aquavella JV, Gasset AR, Dohlman CH. Corticosteroids in corneal wound healing. Am J Ophthalmol 1964; 58: 621-6.

8 François J. Cortisone et tension oculaire. Ann Oculist (Paris) 1954; 187: 805-11.

9 Thygeson P. Hogan MJ, Kimura SJ. Cortisone and hydrocortisone in ocular infections. Trans Am Acad Ophthalmol Otolaryngol 1955; 57: 64-85.

10 Mitsui Y, Hanabusa J. Corneal infections after cortisone therapy. Br J Ophthalmol 1955; 39: 244-50.

11 Moses R. Parkinson G. Schuchardt R. A standard large wound of the corneal epithelium in the rabbit. Invest Ophthalmol Visual Sci 1979; 18: 103-6.

12 Thompson P, Desbordes JP, Giraud JP, Pouliquen Y, Courtois $Y$. The effect of an eye derived growth factor (EDGF) on corneal epithelial regeneration. Exp Eye Res 1982; 34: 191-2.

13 Ho PC. Elliot JH. Kinetics of corneal epithelial regeneration. II. Epidermal growth factor and topical corticosteroids. Invest Ophthalmol Visual Sci 1975; 4: 630-2.

14 Pfister RR, Burstein NL. The effects of ophthalmic drugs. vehicles and preservatives on corneal epithelium. A scanning electron microscope study. Invest Ophthalmol Visual Sci 1976; 15: 246-59.

15 Burstein NL. Corneal cytotoxicity of topically applied drugs. vehicles and preservatives. Surv Ophthalmol 1980; 25: 15-30.

16 Srinivasan BD, Kulkarni JP. The effect of steroidal and non steroidal agents on corneal reepithelialization. Invest Ophthalmol Visual Sci 1981; 20: 688-91.

17 Mitsui Y, Kurihara H, Ohtsubo M. Epithelial punctate keratitis after topical prednisolone. Ophthalmologica 1960; 139: 461-7.

18 Takashima R. Corticosteroids effects on the corneal surface of rabbits studied by scanning electron microscopy.JpnJ Ophthalmol 1975; 19: 393-400.

19 Dorch $W$, Thygeson $P$. The clinical efficacy of Medrysone, a new ophthalmic steroid. Am J Ophthalmol 1968; 65: 74-5.

20 Spaeth GL. Hydroxymethylprogesterone, an anti-inflammatory steroid without apparent effect on intraocular pressure. Arch Ophthalmol 1966; 75: 783-7. 